\title{
Formação de Discentes em Curso de Computação a Distância: Uma Experiência de Extensão Universitária no Ensino das TDIC
}

\author{
Bianca Carneiro Ribeiro ${ }^{1}$, Obionor de Oliveira Nóbrega ${ }^{2}$ \\ ${ }^{1}$ Unidade Acadêmica de Educação a Distância e Tecnologia - Universidade Federal \\ Rural de Pernambuco (UFRPE) \\ Recife - PE - Brasil \\ ${ }^{2}$ Departamento de Computação - Universidade Federal Rural de Pernambuco (UFRPE) \\ Recife - PE - Brasil \\ bianca.ribeiro@ufrpe.br, obionor.nobrega@ufrpe.br
}

\begin{abstract}
This The Communication and Information Digital Technologies are strongly uses in distance learning at Brazil. In this scenario has open issues that involves theoretical and practical aspects on development of skills and competencies necessary for teacher training. This article presents a proposal for university extension action, by the main goal is enabling the student practice teaching in their own Support Poles, resulting in the development of these skills and at the same time a socio-digital transformation in their micro region. There was an increase of up to $115 \%$ in the participation of students and the community in the 2016-2018.
\end{abstract}

Resumo. A EAD no Brasil é uma modalidade fortemente ancorada ao uso das TDIC. Neste cenário, os cursos de licenciatura enfrentam grandes desafios para promover um processo formativo que envolva aspectos teóricos e práticos, que desenvolvam as habilidades e competências necessárias para a formação docente. Este artigo apresenta uma proposta de ação de extensão universitária, com o objetivo de possibilitar ao licenciando a prática docente em seus Polos de Apoio Presencial no ensino das TDIC, permitindo o desenvolvimento destas habilidades e ao mesmo tempo uma transformação sociodigital em sua microrregião. Verificou-se um aumento de até $115 \%$ na participação dos discentes e da comunidade no biênio 2016-2018.

\section{Introdução}

O uso das Tecnologias Digitais de Informação e Comunicação (TDIC) tem-se tornado cada vez mais frequentes no processo de ensino aprendizagem, permitindo uma diversidade de possibilidades na transmissão e recepção do conhecimento. Neste contexto, a utilização de objetos de aprendizagem, recursos educacionais abertos e ambientes virtuais de aprendizagem, passaram a ser fundamentais no campo educacional, permitindo interações síncronas e assíncronas, presenciais e a distância [Teles et al. 2019]. 
De acordo com Mamede-Neves e Duarte (2008), as tecnologias digitais podem contribuir com a tarefa de ensinar, sobretudo no que se refere ao acesso, organização e gestão dos conteúdos a serem ensinados/aprendidos. Neste sentido, a educação a distância (EAD) acomoda-se como uma modalidade educacional fortemente ancorada nas TDIC que, progressivamente, integram os sistemas educacionais [Rosa 2013].

No contexto da EAD, este paradigma educacional traz consigo desafios tanto no eixo do ensino, como também nos eixos da pesquisa e extensão, que deverão ser remodeladas, considerando as características desta modalidade, como a distância do aluno ao Polo de Apoio Presencial, o horário flexível, entre outros [Alonso 2010]. Neste cenário, onde uma ação de Extensão universitária é ainda mais latente e impactante, frente as necessidades das comunidades dos interiores dos estados brasileiros, projetos que visem o fortalecimento destas ações devem ser considerados de extrema relevância [Maciel 2010; Albuquerque 2016; Lins 2016].

Nesta conjuntura, os cursos de licenciatura vêm enfrentando grandes desafios para promover um processo formativo coerente com as exigências postas pela contemporaneidade demandando a formação de um indivíduo e um profissional criativo, autônomo, crítico, inovador [Teles et al. 2019]. Na modalidade a distância o desafio é ainda maior, uma vez que a formação de professores e sua relação com o exercício da docência têm ampliado as discussões no meio acadêmico, envolvendo aspectos teóricos e práticos relacionados ao currículo dos cursos, seus diferentes conceitos e concepções, formas de organização e operacionalização [Araújo et al. 2017].

Desta forma, torna-se fundamental que os licenciados, na modalidade a distância, atinjam as habilidades e competências necessárias para a formação docente, por meio de ações de extensão universitária que permitam a participação do licenciado na prática docente em seus Polos de Apoio Presencial, possibilitando ao mesmo tempo uma transformação sociodigital em sua microrregião [Alves e Silva 2017].

Neste sentido, o presente artigo apresenta uma proposta de uma ação de extensão universitária no ensino das TDIC, durante a formação de discentes do curso de Licenciatura em Computação (LC), na modalidade a distância, da Unidade Acadêmica de Educação a Distância e Tecnologia da Universidade Federal Rural de Pernambuco.

Estruturalmente, o artigo está dividido em cinco seções. Após as considerações introdutórias, na seção seguinte é apresentado o contexto da extensão na educação universitária a distância no país. Na terceira seção discutem-se, de forma detalhada, a metodologia utilizada na ação de extensão universitária. Na seção quatro é apresentada uma análise e discussão com os resultados obtidos. Por fim, na seção cinco são apresentadas as considerações finais desse artigo.

\section{2. $O$ contexto da extensão Universitária e na EAD no Brasil}

Atualmente no Brasil, o eixo fundamental das universidades é formado pelo tripé: ensino, pesquisa e extensão, que deve obedecer ao princípio da indissociabilidade segundo o artigo 207 da Constituição Brasileira de 1988 [Brasil 2019], e essas funções básicas merecem igualdade em tratamento por parte das instituições de ensino superior, tanto na esfera de graduação, quanto na Pós-graduação [Moita 2009]. 
De acordo com Paula (2013), dentre as três dimensões deste tripé, a Extensão permanente e sistematicamente convoca a universidade para o aprofundamento de seu papel como instituição comprometida com a transformação social, aproximando a produção e a transmissão de conhecimento de seus efetivos destinatários, cuidando de corrigir, nesse processo, as interdições e bloqueios, que fazem com que seja assimétrica e desigual a apropriação social do conhecimento, das ciências, das tecnologias.

Porém, apesar da importância da extensão para a formação acadêmica em quaisquer modalidades (presencial ou a distância), segundo Machado (2013) percebeuse uma lacuna existente nos cursos a distância das instituições públicas de ensino superior fomentados pelo Sistema da Universidade Aberta do Brasil (UAB), no que se refere a interligação deste tripé.

Desta forma, o desenvolvimento de ações de extensão em educação a distância nas universidades públicas brasileiras não devem estabelecer caminhos únicos e precisos como solução estática e imutável, mas levantar considerações que indiquem eventuais direções para as atividades extensionista, pois deve-se considerar os aspectos social e intraestrutural da microrregião como um fator impactante no resultado destas ações, assim como, devem sempre considerar os polos (discentes e comunidade) como unidades únicas e especiais [Cunha 2017].

Nesse sentido, acredita-se ser possível o desenvolvimento de ações em três vertentes: ações desenvolvidas por discentes de cursos da EAD para oferta presencial no Polo de Apoio Presencial; ações desenvolvidas por discentes de cursos EAD para oferta de público virtual; e ações desenvolvidas pela universidade (presencial) para oferta ao público virtual [Silva et al. 2017].

\section{Metodologia}

A ação de extensão bienal aqui apresentada foi inicialmente criada no ano de 2016, por meio de um evento denominado EduTec Day - Educação e Tecnologia, no qual os discentes do curso de Licenciatura em Computação pudessem participar como palestrantes e ministrantes de oficinas e/ou minicursos, sendo orientados pelo coordenador e/ou docentes do curso. Conforme ilustra a Figura 01, este evento visou promover um dia de interação entre os docentes e discentes de Licenciatura em Computação com a comunidade local e de municípios adjacentes, de maneira a disseminar os conhecimentos voltados para a área da Educação e TDIC por meio de palestras, oficinas e minicursos a serem ofertados nos municípios em que existam polos de apoio presencial do curso.

O evento destinou-se a professores das microrregiões dos polos de apoio presencial, profissionais de educação e tecnologia, estudantes de graduação e comunidade em geral interessados na temática apresentada, tendo como objetivo principal o desenvolvimento regional buscando o comprometimento da comunidade universitária com interesses e necessidades da sociedade, e estabelecendo mecanismos que relacionem o saber acadêmico ao saber popular. 


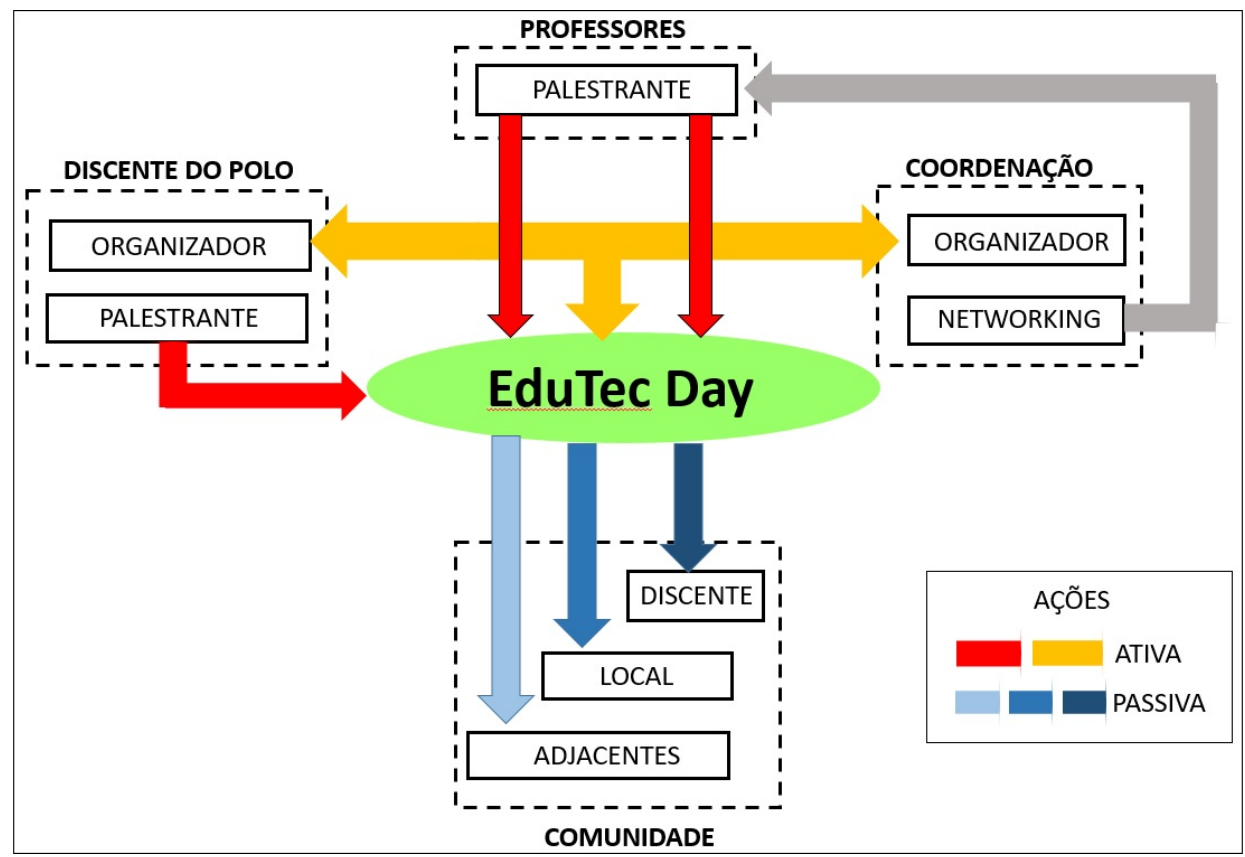

Figura 01. O modelo de ação de Extensão: EduTec Day

Para que ocorresse a execução desta ação de extensão universitária foi fundamental que existisse o interesse dos discentes (de cada Polo), uma vez que, por ser um modelo de educação a distância, há a necessidade de se criar mecanismos de participação diferenciados do presencial, resultando em uma maior participação dos estudantes com ações de organização de eventos educacionais, planejamento, didática, entre outros, que visam estimular habilidades como pro-atividade, liderança, trabalho em equipe, interdisciplinaridade e inter-relacionamento. Caso não existisse interesse de discentes de um determinado polo participar deste evento, o mesmo não era ofertado no respectivo polo.

A participação dos discentes poderia ocorrer de forma passiva, onde o mesmo poderia participar apenas como ouvinte, ou de forma ativa, podendo organizar o evento ou ministrar a atividade de palestrante do evento. A Figura 02 apresenta um mapa mental que ilustra a participação dos principais atores e suas funções. Para participar como organizador do evento, o discente realizou as etapas descritas a seguir:

- Etapa 01: Para a participação de um polo na ação de extensão era necessário no mínimo um discente como representante deste polo (no máximo 02 discentes representantes por Polo), possibilitando também a participação (não obrigatória) conjunta do tutor presencial do polo.

- Etapa 02: Os discentes interessados em participar da organização do evento no polo, deveriam preencher um documento contendo uma proposta para organização do evento e enviar para a Coordenação do Curso, contendo os dados pessoais do(s) interessado(s).

- Etapa 03: Os organizadores de cada polo ficaram responsáveis pela divulgação do evento no município do polo e contaram com o apoio da Coordenação do Curso e da Unidade Acadêmica de Educação a Distância e Tecnologia na divulgação no site da Unidade Acadêmica e suas redes sociais. A Coordenação 
do Curso, junto com a equipe de ilustração da Unidade Acadêmica de Educação a Distância e Tecnologia ficaram responsáveis pela criação e desenvolvimento do material de divulgação impresso (cartazes, folders).

- Etapa 04: Os organizadores de cada polo ficaram responsáveis pela verificação da disponibilidade do espaço físico, vagas, horários, planejamento geral e organização no dia do evento em seus respectivos polos. As informações foram centralizadas na Coordenação do Curso para produção do material de divulgação.

- Etapa 05: Ao final do evento cada organizador entregou um relatório final à coordenação do curso como feedback para análise e futuras modificações.

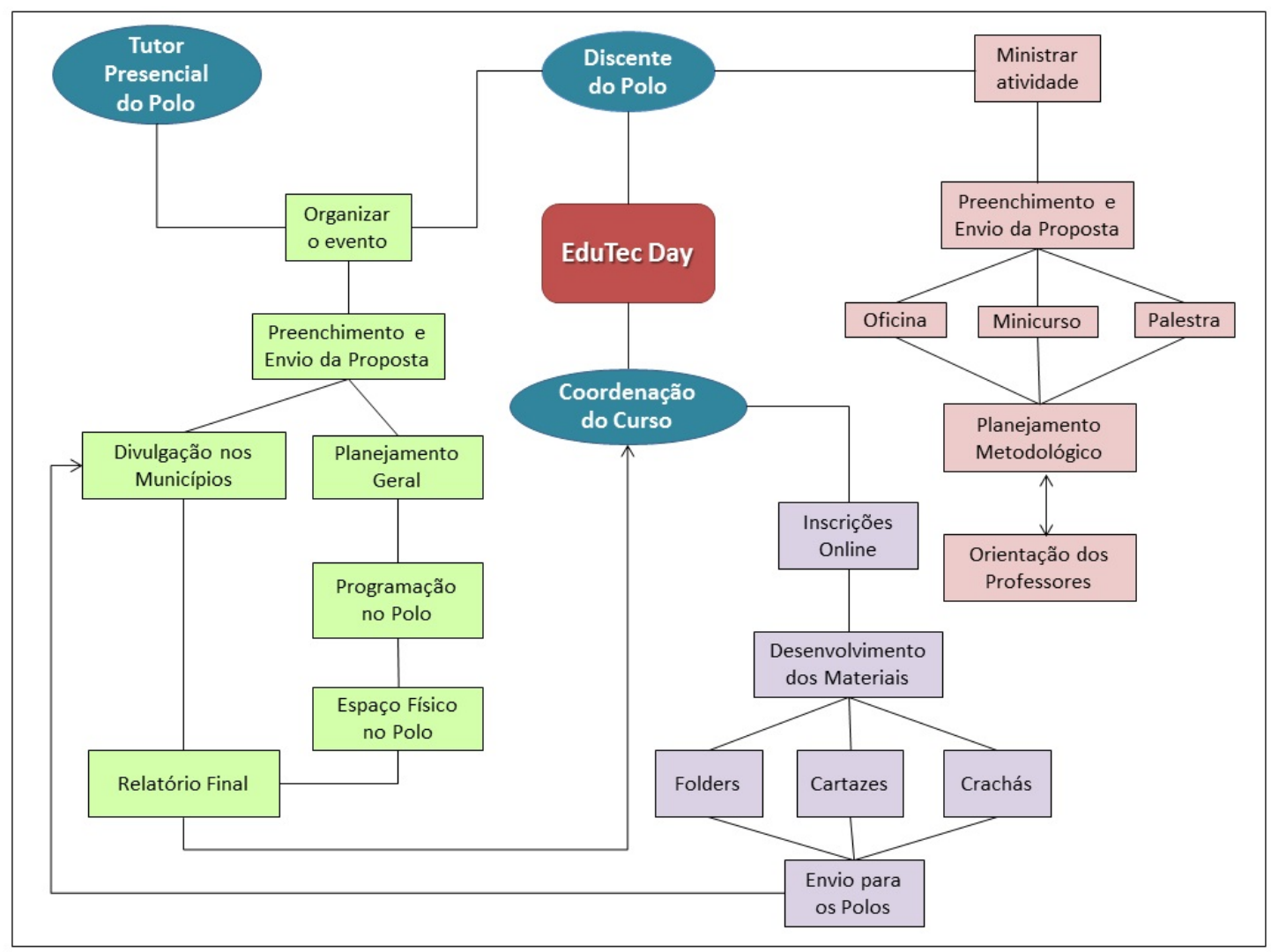

Figura 02. Mapa mental da ação de extensão universitária - EduTec Day

Para atuar como palestrante nas atividades do evento, o discente realizou as seguintes etapas:

- Etapa 01: Os alunos interessados em participar enviaram para a Coordenação do Curso a proposta de atividades a serem realizadas no evento classificando-as como: Oficinas, Minicursos ou Palestras, que estivessem relacionados ao tema TDIC e/ou Educação.

- Etapa 02: Esta proposta contemplava informações detalhadas da atividade contendo carga horária, tema, público-alvo, objetivo geral e específicos, metodologia e recursos necessários, que foram devidamente acompanhados, 
analisados e orientados pelos professores da área dos temas escolhidos, verificando a relevância e preparo da atividade para a sociedade.

A participação dos docentes do curso também era prevista, caso os mesmo demonstrassem interesse, podendo participar do evento para ministrar atividades que contribuíssem para o enriquecimento do evento e disseminação do conhecimento para a sociedade.

Após a etapa de seleção dos polos, dos organizadores e ministrantes do evento, a Coordenação do Curso definiu a data do evento e das inscrições diante da disponibilidade do espaço físico dos polos de apoio presencial. Em seguida, os organizadores encaminhavam a programação de cada polo, com horários, temas e número de vagas que seriam permitidas por atividade.

Com estas informações, a Coordenação do Curso, junto com a equipe de produção da Unidade Acadêmica de Educação a Distância e Tecnologia, iniciava a criação e desenvolvimento dos materiais do evento. Dentre estes materiais, destacam-se os mais utilizados: Folders com a programação de cada polo, Cartazes e Crachás. Com os materiais confeccionados, estes foram enviados aos polos para os organizadores divulgarem no município do polo e nas cidades circunvizinhas. Além dos cartazes e folders, como meio de divulgação utilizou-se redes sociais, grupos de whatsapp e marketing digital por e-mail.

Durante o período das inscrições, que foram realizadas de forma on-line por meio de um formulário, a coordenação acompanhava sistematicamente e repassando números parciais aos organizadores de cada polo, que verificavam a necessidade, ou não, de intensificar a divulgação do evento.

Nos anos de 2016 e 2018, esta ação de extensão foi promovida nos municípios de Tabira, Palmares, Recife e Limoeiro. Nestes polos, diversos temas foram escolhidos e trabalhados pelos alunos e professores convidados, resultando em atividades como palestras, oficinas e minicursos. A listagem das atividades ofertadas no EduTec Day em ambas as edições são apresentadas no Quadro 01.

Quadro 01: Atividades ofertadas no EduTec Day

\begin{tabular}{|c|l|l|}
\hline Polo & Atividade & \multicolumn{1}{|c|}{ Tema } \\
\hline \multirow{5}{*}{ Tabira } & Minicurso & Computação em Nuvem \\
\cline { 2 - 3 } & Oficina & A utilização dos micro controladores em Projetos de Robótica \\
\cline { 2 - 3 } & \multirow{3}{*}{ Palestras } & Jogos eletrônicos e educação \\
\cline { 3 - 3 } & & A importância das Novas Tecnologias para a Educação \\
\cline { 3 - 3 } & & $\begin{array}{l}\text { Downex: É possível auxiliar a alfabetização de pessoas com } \\
\text { Síndrome de Down? }\end{array}$ \\
\cline { 2 - 3 } & Minicurso & Introdução aos Conhecimentos Básicos de Hardware \\
\hline \multirow{4}{*}{ Palmares } & Oficina & Manutenção Preventiva \\
\cline { 3 - 3 } & \multirow{4}{*}{ Palestras } & Jogos de Raciocínio Lógico: uma introdução a programação \\
\cline { 3 - 3 } & & Backup de Dados \\
\cline { 3 - 3 } & & T.I Verde, um olhar para o futuro \\
\cline { 3 - 3 } & & Segurança de Redes Wifi \\
\cline { 3 - 3 } & & Curriculo 2.0 - Linkedin \\
\hline
\end{tabular}




\begin{tabular}{|c|c|c|}
\hline & & $\begin{array}{l}\text { Meios Tecnológicos, uma abordagem histórica progressiva na } \\
\text { sociedade }\end{array}$ \\
\hline \multirow{3}{*}{ Limoeiro } & Minicurso & $\begin{array}{l}\text { Crimes Cibernéticos: o que são, como se prevenir e como proceder } \\
\text { diante deles }\end{array}$ \\
\hline & \multirow[t]{2}{*}{ Palestras } & Computação Jurídica: É possível construirmos robôs-juízes? \\
\hline & & Segurança da Informação \\
\hline \multirow{3}{*}{ Recife } & Minicurso & Design básico para apresentações em Datashow \\
\hline & \multirow{2}{*}{ Oficinas } & Tendências Tecnológicas e Inovação Educacional \\
\hline & & 7P - Por quê Programar? Python para Primeiros Passos \\
\hline
\end{tabular}

\section{Análise e discussão dos resultados obtidos}

Após a realização do evento, observou-se a importância e necessidade de dar continuidade com esta ação, tendo em vista os feedbacks positivos recebidos dos participantes, assim como, um aumento das inscrições, com o decorrer das edições do evento, como ilustra o Gráfico 01 , onde verifica-se um aumento de inscrições de $142 \%$ no polo Tabira e 57\% no Polo Palmares entre os anos de 2016 e 2018. Dentre os retornos positivos relatados, destacam-se:

- A relevância dos temas abordados;

- Qualidade das atividades ministradas;

- Inclusão da comunidade em atividades tecnológicas;

- O estímulo à reflexões acerca do uso da tecnologia;

Gráfico 01: Participação da comunidade no EduTec Day - Bienal 2016-2018

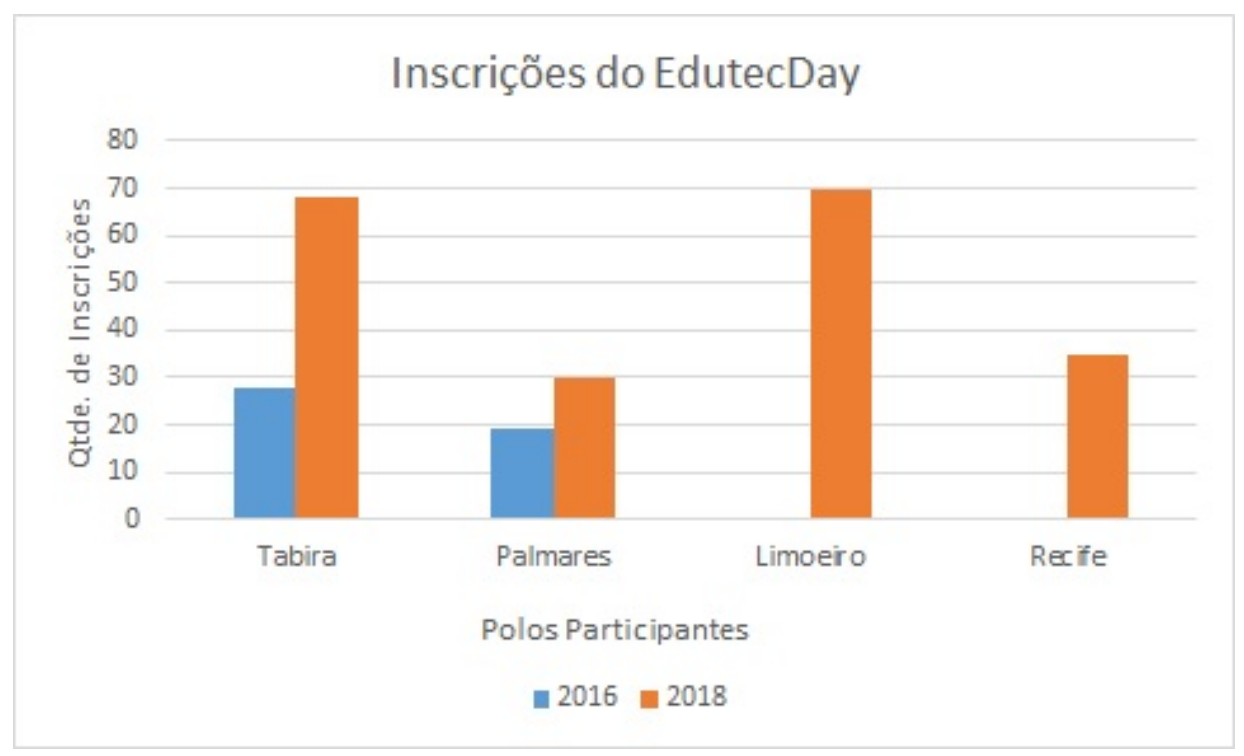

Percebeu-se que os principais pontos de divulgação, que abrangem maior número de interessados, são as escolas, rádio da cidade e grupos de whastapp, assim como, averiguou-se que os participantes não limitam-se a residentes do município onde 
o evento está ocorrendo, mas que há presença de pessoas de cidades circunvizinhas do município do polo.

O Gráfico 02 ilustra a participação dos discentes comparados a evasão. Verificase um crescimento de $115 \%$ na participação efetiva das atividades no Polo de Tabira e 40\% no Polo de Palmares no biênio 2016-2018. Observou-se também que o maior número de participantes esteve presente nos polos mais distantes da capital. O polo Recife foi onde se obteve menor número de participantes e no polo Tabira, o maior número. Acredita-se que este fato esteja relacionado a falta de oportunidades de eventos acadêmicos para os residentes das cidades mais distantes da capital, o que reflete a importância da educação a distância e de ações de extensão como estas.

\section{Gráfico 02: Participação x Evasão}

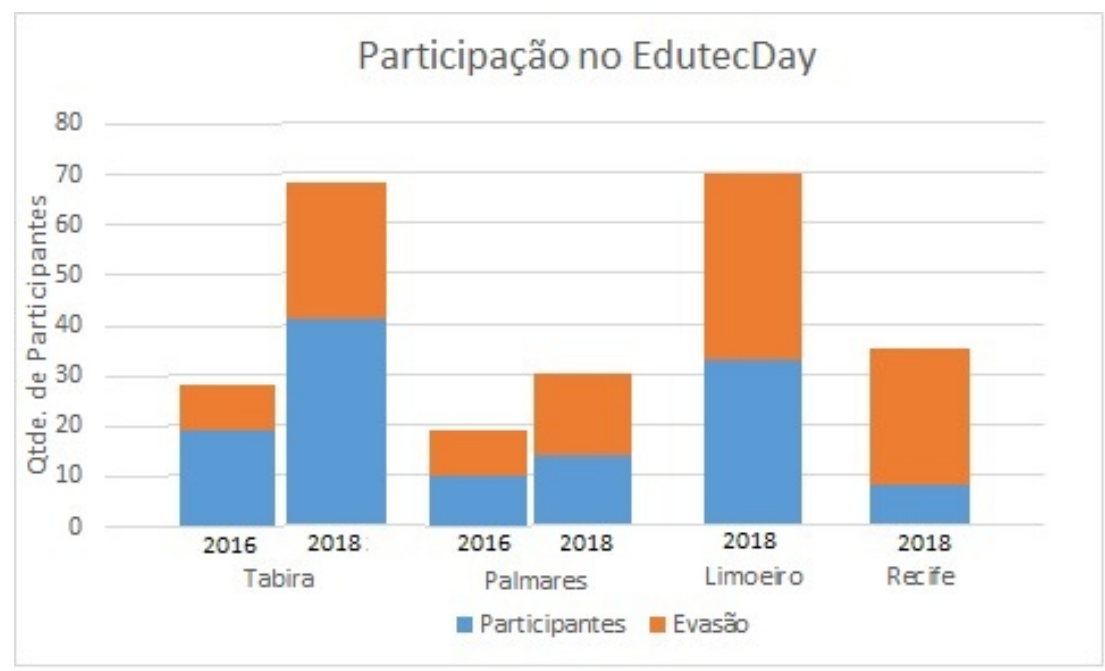

Uma característica observada a ser aprimorada no evento foi a evasão, levando em consideração o número de inscritos, como pode ser observado no Quadro 02.

Quadro 02: Evasão no EduTec Day

\begin{tabular}{|c|c|c|}
\hline Polos & $\mathbf{2 0 1 6}$ & $\mathbf{2 0 1 8}$ \\
\hline Tabira & $32 \%$ & $40 \%$ \\
\hline Palmares & $47 \%$ & $53 \%$ \\
\hline Limoeiro & - & $53 \%$ \\
\hline Recife & - & $77 \%$ \\
\hline
\end{tabular}

Devido a inscrição ser on-line e gratuita, ocorreram situações em que vários participantes se inscreveram, porém não compareceram, resultando uma ausência no evento de $40 \%$ no polo de Tabira, chegando até $77 \%$ no polo de Recife.

Estuda-se a possibilidade de condicionar a inscrição do evento à doação de $1 \mathrm{~kg}$ de alimento não perecível a ser entregue ao final do evento para uma instituição de 
caridade. Porém, neste caso as inscrições teriam que ser presenciais, ou ao menos sua confirmação, o que poderia prejudicar possíveis participantes das cidades circunvizinhas devido a distância e dificuldade de deslocamento. Diante deste impasse, outras possibilidades deverão ser analisadas pela coordenação, docentes e discentes do curso, para as próximas edições do evento obterem uma maior taxa de participação e menor evasão.

\section{Considerações Finais}

$\mathrm{Na}$ busca por atividades que contribuam para o fortalecimento da indissociabilidade do tripé Ensino, Pesquisa e Extensão, na modalidade a distância, assim como, ações que proporcionem que discentes de um curso de licenciatura, na modalidade a distância, atinjam as habilidades e competências necessárias para a formação docente, o curso de Licenciatura em Computação (LC) da Unidade Acadêmica de Educação a Distância e Tecnologia da Universidade Federal Rural de Pernambuco criou uma ação de extensão universitária denominada EduTec Day, cujo objetivo foi proporcionar aos discentes uma prática docente por meio da participação direta na organização de um evento para o ensino das TDICs, ressaltando a importância das ações de extensão na esfera da graduação.

Ressalta-se que o engajamento dos discentes como organizadores e ministrantes, e o comprometimento na disseminação do ensino das TDIC são primordiais para relevância e sucesso na execução desta ação de extensão que favorece o preparo dos licenciandos como futuros educadores, onde aplicam seus conhecimentos à realidade regional e fortalecem o vínculo entre as atividades de ensino, pesquisa e extensão, contribuindo para que o profissional esteja sempre apto a vencer desafios e a resolver questões pertinentes à sua área de atuação.

Destaca-se também que o aumento da participação da comunidade mostra a importância frente as necessidades de transformação sociodigital nas comunidades dos interiores dos estados brasileiros, e o aumento da adesão dos discentes ratifica o fortalecimento desta ação de extensão na formação de professores e sua relação com o exercício da docência envolvendo aspectos teóricos e práticos relacionados ao currículo da licenciatura.

\section{Referências}

Alonso, K. M. (2010) “A Expansão do Ensino Superior no Brasil e a Ead: Dinâmicas e Lugares”. Educ. Soc., Campinas, v. 31, n. 113, p. 1319-1335, out.-dez.

Albuquerque, I.M.N.; Cavalcante, A. S. P. e Ribeiro, M.A.(2016) "Desencontros e Encontros Sobre Extensão Universitária à Luz da Pedagogia de Paulo Freire”. Essentia, Sobral, v. 17, n. 1, p. 158-186.

Alves, E.J. e Silva, B.D.(2017) "Formação Docente Online: a inclusão sociodigital para além do acesso às tecnologias digitais de informação e comunicação". Revista PanAmazônica de Comunicação. Vol 1, n. 2.

Araújo, G.C., SANTOS, D.S., SALES, M. A. (2017) "Da Formação à Docência: Os Desafios dos Cursos de Licenciatura na Contemporaneidade”. XIII Congresso Nacional de Educação. p. 10678-10692. 
Brasil (1988). Constituição Brasileira de 1988. Acesso em: 20 fev. 2020. Disponível em: http://www.planalto.gov.br/ccivil_03/Constituicao/Constituicao.htm.

Cunha, E.J.L.,(2017) "O Desenvolvimento das Ações de Extensão em Educação A Distância nas Universidade Públicas Brasileiras. Extensão Universitária na EAD” Desafios e Experiências da indissociabilidade entre pesquisa, ensino e extensão. Editoraufmg, p 11-15.

Lins, R.R. et al.(2016) “A Experiência de Implantação de Atividades de Extensão no Bacharelado em Administração Pública da Universidade Federal Rural de Pernambuco". Anais do $22^{\circ}$ Congresso Internacional de Educação a Distância CIAED.

Machado, M. R. L. et al.(2013). "A importância dos programas de extensão para formação universitária a distância”. In: Congresso Brasileiro De Ensino Superior a Distância (ESUD 2013), Belém.

Maciel, L. R.(2010). "Política Nacional de Extensão: perspectivas para a universidade brasileira". Revista ParticipAção. v. 18, p. 17-27.

Mamede-Neves, M. A. e Duarte, R.(2008) "O Contexto dos novos Recursos Tecnológicos da Informação e Comunicação e a Escola. Revista Educação e Sociedade, Campinas, Vol29, n.104 - Especial, p. 769 - 789.

Moita, F.M.G.S.C. e Andrade, F.C.B.(2009) "Ensino-Pesquisa-Extensão: Um Exercício de Indissociabilidade na Pós-Graduação". Revista Brasileira de Educação v. 14 n. 41 maio/ago.

Paula, J.(2013) "A Extensão Universitária: História, Conceito e Propostas". Interfaces Revista de Extensão, v. 1, n. 1, p. 05-23, jul./nov

Rosa, S. (2013) "A influência das TDIC na (re)configuração de Modelos de EaD tradicionais para Educação online". Revista Novas tecnologias na Educação. Volume 11, n.3.

Silva, L.E, Nogueira, L.A.G. e Barbosa, C.S.F.(2017) "Algumas Reflexões e Apresentação de Propostas de Programas de Extensão para o Ensino a Distância". Extensão Universitária na EAD - Desafios e Experiências da indissociabilidade entre pesquisa, ensino e extensão. p 17-24. Editoraufmg.

Teles, G., Soares, D.M.R., Lima, L. e Loureiro, R.C.(2019) "Docência e Tecnologias Digitais na Formação de Professores: Planejamento e Execução de Aulas por Licenciados". IV Congresso sobre Tecnologia na Educação. Recife. 